\title{
Commentary: Maximizing response and outcomes in multimodality therapy for locally advanced esophageal adenocarcinoma
}

\author{
Wayne L. Hofstetter, MD \\ From the Department of Thoracic and Cardiovascular Surgery, University of Texas MD Anderson Cancer Center, \\ Houston, Tex. \\ Disclosures: Author has nothing to disclose with regard to commercial support. \\ Received for publication Dec 4, 2018; accepted for publication Dec 4, 2018; available ahead of print Jan 11, 2019. \\ Address for reprints: Wayne L. Hofstetter, MD, Thoracic Surgery, MD Anderson Cancer Center, 1515 Holcombe \\ Blvd, Unit 445, Houston, TX 77030 (E-mail: whofstetter@mdanderson.org). \\ J Thorac Cardiovasc Surg 2019;157:1694-5 \\ $0022-5223 / \$ 36.00$ \\ Copyright $(2) 2018$ by The American Association for Thoracic Surgery \\ https://doi.org/10.1016/j.jtcvs.2018.12.018
}

Groth and colleagues ${ }^{1}$ have adeptly explored interesting questions within the realm of multimodality therapy for locally advanced esophageal adenocarcinoma. Namely, how primary tumor and nodal response to neoadjuvant therapy modifies survival and the potential interaction of these effects on treatment strategy. A priori, these are important questions, because histopathologic response is a variable that is independently affected by the type of therapy chosen and can be directly tied to outcome. The immediate posttreatment pathologic assessment (ypTNM) is a surrogate endpoint with some reliability in predicting long-term outcome. This has been previously reported and is now reflected in the American Joint Commission on Cancer 8th Edition Staging Manual. ${ }^{2}$ By deduction, one could reason that improving treatment response will improve outcome and that choosing therapy that results in the best locoregional response will therefore lead to better survival. But is this actually the case with our current choices?

As a treatment paradigm, multimodality chemoradiation and surgery is focused on and effective in controlling locoregional disease. But even patients who have attained a complete pathologic response to neoadjuvant chemoradiation frequently fail systemically, albeit less so than incomplete responders. ${ }^{3}$ It is important to recognize that the presence of nodal disease and response to therapy is reflective of prognosis because it is an indicator of systemic disease. The problem is that we have yet to fully address hematogenous spread.

Perioperative chemotherapy is given at greater doses than combined chemoradiation, and it is intended to control disease in patients who are highly susceptible to hematogenous recurrence. In fact, several randomized trials have shown that pre/perioperative chemotherapy improves overall survival compared with surgery alone. ${ }^{4}$ An ongoing debate is the comparative efficacy of chemoradiation versus chemotherapy and whether additional systemic therapy in the form of neoadjuvant or adjuvant chemotherapy could improve on response to initial therapy. In as much as the current manuscript by Groth and collegues ${ }^{1}$ leans heavily

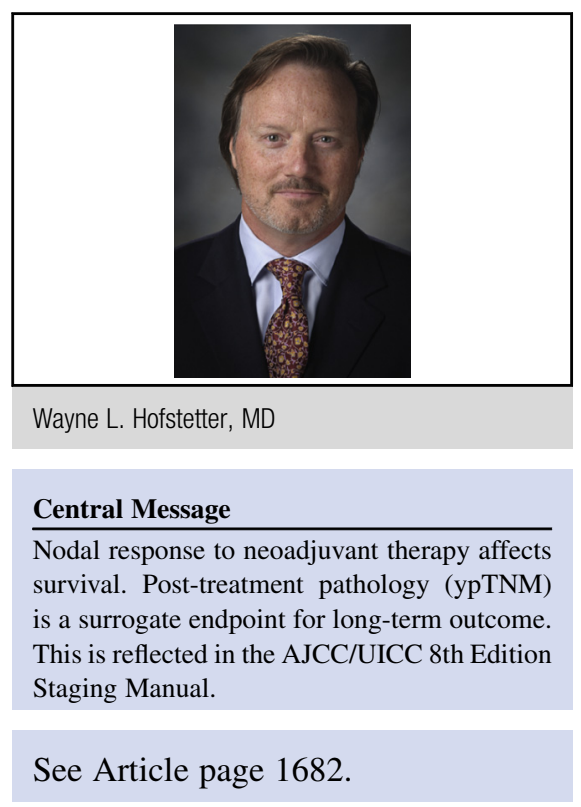

on suggesting chemoradiation up front and consideration for adjuvant therapy in patients with residual nodal disease, this is hypothesis-generating. These data are from a retrospective review of a national database that inherently contains heterogeneity that may not be accounted for nor corrected. ${ }^{1}$

I do agree that chemoradiation has consistently shown better R0 resection rates compared with chemotherapy alone, but I would not wish to extrapolate on data like these. In August of 2018, the NeoRes study (Neoadjuvant Chemotherapy Versus Radiochemotherapy for Cancer of the Esophagus or Cardia) reported no survival advantage comparing preoperative chemoradiation with chemotherapy. ${ }^{5}$ The Neo-AEGIS study (NEOadjuvant trial in Adenocarcinoma of the oEsophagus and oesophagoGastric junction International Study) is another larger randomized controlled trial comparing preoperative chemotherapy versus chemoradiation utilizing the current best practices, but it is not yet complete. ${ }^{6} \mathrm{I}$ am willing to concede that there may be advantages to either treatment approach, and I anxiously await the results of trials comparing the 2 strategies. Moreover, I am also hopeful that methods of residual disease detection using advanced magnetic resonance imaging techniques and/or liquid biopsy become meaningful in our practices, so that we can know where and in whom to focus specific therapies. 


\section{References}

1. Groth S, Burt BM, Farjah F, Smaglo BG, Sada YH, Sugarbaker DJ, et al. Prognostic value of neoadjuvant treatment response in locally advanced esophageal adenocarcinoma. J Thorac Cardiovasc Surg. 2019;157:1682-93.e1.

2. Rice TW, Ishwaran H, Kelsen DP, Hofstetter WL, Apperson-Hansen C, Blackstone EH, Worldwide Esophageal Cancer Collaboration Investigators. Recommendations for neoadjuvant pathologic staging (ypTNM) of cancer of the esophagus and esophagogastric junction for the 8th edition AJCC/UICC staging manuals. Dis Esophagus. 2016;29:906-12.

3. Blum Murphy M, Xiao L, Patel VR, Maru DM, Correa AM, G Amlashi F, et al. Pathological complete response in patients with esophageal cancer after the trimodality approach: the association with baseline variables and survival-The University of Texas MD Anderson Cancer Center experience. Cancer. 2017;123:4106-13.
4. Ronellenfitsch U, Schwarzbach M, Hofheinz R, Kienle P, Kieser M, Slanger TE et al; GE Adenocarcinoma Meta-analysis Group. Perioperative chemo(radio)therapy versus primary surgery for resectable adenocarcinoma of the stomach, gastroesophageal junction, and lower esophagus. Cochrane Database Syst Rev 2013;5: CD008107.

5. von Döbeln GA, Klevebro F, Jacobsen AB, Johannessen HO, Nielsen NH, Johnsen G, et al. Neoadjuvant chemotherapy versus neoadjuvant chemoradiotherapy for cancer of the esophagus or gastroesophageal junction: long-term results of a randomized clinical trial. Dis Esophagus. August 22, 2018 [Epub ahead of print]. 6. Reynolds JV, Preston SR, O’Neill B, Baeksgaard L, Griffin SM, Mariette C, et al ICORG 10-14: NEOadjuvant trial in Adenocarcinoma of the oEsophagus and oesophagoGastric junction International Study (Neo-AEGIS). BMC Cancer. 2017; 17:401. 